Volume 8. No. 8, August 2020

International Journal of Emerging Trends in Engineering Research

Available Online at http://www.warse.org/IJETER/static/pdf/file/ijeter96882020.pdf

https://doi.org/10.30534/ijeter/2020/96882020

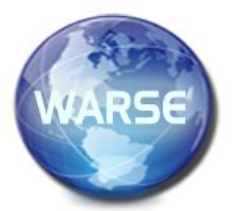

\title{
Smart Sleep Monitoring System
}

\author{
Chhavi Saksena, Farhaj Rehana, Kanimozhi G and Umayal.C \\ School of Electrical Engineering, VIT Chennai, Tamil Nadu, India, \\ kanimozhi.g@vit.ac.in
}

\begin{abstract}
Nearly one-third of human life is spent on sleeping, an easily reversible state of relative unresponsiveness and stillness which occurs more or less regularly and cyclically each day. A great sleep can subsidize countless positive outcomes, like better overall health, less sluggishness during the day, along with better mental health. The kind of sleep affects the health of the patient. Monitoring vital functions, like body temperature and sweating during sleep, is very important for sleep monitoring and clinical diagnosis. Smart pillows provide a relatively easy way to control sleep by placing humidity sensors and temperature in strategic locations. The patient's daily sleep information is very helpful in making decisions about diagnosis and treatment. Consumers can check their data with healthcare providers and gradually change their sleep habits. One can keep a check on their body condition when they sleep under various environmental parameters (humidity, brightness and temperature). The results indicate that one sleeps best in a dark and cool environment.
\end{abstract}

Key words: Arduino, Humidity, Luminosity, Motion, Non-invasive monitoring system, NREM, REM, Sleep monitoring, Sleep stages, Temperature.

\section{INTRODUCTION}

As per the generic interpretation, sleep is one of the activity of brain whose goal is to re-establish weariness in brain [1]. A quality sleep can add to numerous positive results, like improved overall wellbeing, diminished daytime sleepiness, and improved emotional health [2]. Sleep disorders that previously attacked older people now attack everyone, from children to senior citizens and the result is known. An incomplete list of diseases that positively affect sleep disorders include obesity, diabetes, high blood pressure, cardiovascular disease, stroke, immune dysfunction, etc. [3],[4]. For developed countries, this is not only a matter of healthcare but also an economic problem in various nations [5]. Even with these many numbers of adverse effects, a mere 7 per cent of the population meets the criterion of episodic insomnia, defined as an obstacle in inducing and/or maintaining sleep for a period of minimum one month[6]. Several symptoms of a sleep disorder include short periods of sleep, a non-restorative sensation of sleep and sleepiness during daylight hours. The popularity of insomnia [7] confide in the criteria that characterize it and the surveyed population studied, although a community-based research consensus indicates that about 30 per cent of grownups experience one or higher number of insomnia symptoms. Technologies are implementing lifestyle changes in this knowledge \& communication era, particularly the smartphones, laptops, and/or tablets are brought into the sleeping area. This had a adverse effect on the bedroom environment which is sleep-friendly [8] since National U.S. studies carried out in the past 50 years have demonstrated a decrease in self-reported sleep duration of 1.5 to 2 hours [9]. In addition to the previously listed health problems related to disturbances in sleep, multiple fallouts should be displayed. In young children and adolescents, this sufficient decrease in sleep has precipitated temperature problems such as hyperactivity illness, attention deficit behavioral issues and issues in memorizing, all of which ends up in a significant blow on performance in gaining knowledge [10]. In young people attending college, along with the outcomes that have an effect on kids and young adults, depression and impaired social relationships are observed [11], [12]. In adults, the above symptoms which decrease productivity and escalate absenteeism and accidents at work [8]. Sleep problems can be seen based on these issues as a public wellness headache, rising education expenditure and cost of health care, and cut down efficiency in the job environment. As a consequence, sleep disturbance diagnosis is important for improving the well-being of the population.

There are three main factors [13] that affect the abnormalities in sleep which might be mental, environmental and physiological. Sleeping disorder psychological elements are usually short-term and include stress which is the number one cause in a mental issue. The physiological aspect involves changes in physiological systems which affect sleep quality. This factor can occur due to nervous system differences, immune system, brain activity, cardiovascular and metabolic system discrepancies. Finally, environmental aspects that include an environmental specification like light, humidity, temperature, and various other environmental aspects, adding the comfort of the house, calmness or maybe sound that makes anyone has the feeling to sleep. The need for long distant health management systems is fast receiving acceptance in the medical community with the advent of a globally ageing society. Recognizing networks, sensors and big-data analytics that has created a strong basis for an health system that is interconnected. The issue that demands change is that how someone cannot invasively and unobtrusively 
detect physiological signals. Since one-third of a human's life is expended on sleep, which is why sleeping habit and its quality influences wellbeing and the drawbacks of too little sleep or too much sleep and the value of sleep are considered extremely.

A physiological shift during sleep is a momentous safety predictor but is strenuous to observe with conventional methods. For warmth, a pillow is used to support the head during sleep. So, if data could be recorded from the pillow with the no-perception condition, it ends up to be a direct, efficient, and non-invasive method to study health and sleep. The current article focuses on the control of temperature of the body, which happens to be one of the crucial physiological symptoms essential for clinical diagnosis. The present paper contributes a straightforward method of monitoring the sleep conditions by using the humidity and temperature sensors implanted within the pillow. Experiments by different individuals demonstrate that the inferred and statistical results accurately resonate abnormal and normal sleep cases.

\section{SLEEP ASSESSMENT}

Standard sleep disorder evaluation normally includes a real checking. The history of sleep issue that gives details if that is persistent or transient and sleep log which is a description of the daily routine of the person that also includes bedtime, estimated sleep start time which is the duration for which a person sleeps, the timing and amount of awakening, and the point of final awakening [14]. Sleep logs usually compel the person make a nightly commitment of 2 weeks which may become taxing. Some techniques like wrist actigraphyare used to monitor sleep patterns [15] and polysomnographic recording of sleep in a sleep lab. In the initial example, loss of data happens when the individual misses wearing the actigraph where showers are extremely easy to mistake for sleep just before bedtime or after wake-up time if the person is not keeping a record in-depth. In the next case, monitoring sleep is trickier with the elderly in the lab because they may find it more difficult to fall asleep in a lab. Even if few sleep patterns can be tested efficiently in a lab setup, for example, sleep apnea, the presence of a person inside the laboratory can perturb routine sleep patterns of that individual. Moreover, this is not continuous but a periodic evaluation.

\subsection{A straightforward anamnesis}

As for the assessment of sleep, several studies are carried out using surveys, anamnesis and self-reports. Familiar questions used over a period for determining sleep quality are:

1. Are sleep difficulties reported?

2. When do you go to bed?

3. Time at which you sleep daily.

4. Time at which you were waking up.

5. Time at which you come out o bed.

6. The number of times have you been waking up over the night?
7. Have you dreamt?

8. Have you ever felt rejuvenated after sleep?

The first two questions related to sleep disorders and the explanation for the need for further research is if the person feels better after sleep. Questions numbered 2-3 are essential to the diagnosis of sleep disorders linked to sleeping difficulties. The difference in time between lying down and going to dormant mode reflects the duration of sleep, as discussed previously, temperature and luminosity, among various other behavioral patterns, which has a great influence on this dimension. Questions numbered 3-6 seek to assess the efficiency of sleep-time. The difference in time between the data collected in Questions from 3-4 provides a more authentic idea of how long you are sleeping. Questions with numbers 5 as well as 6 provide a crucial clue to the concept of self. Question number 6 is important to examine the sleep disturbance that can be induced by various factors such as nocturia which is the need to wake up at night and pass urine [16]; and somnambulism, individuals with somnambulism typically do not have the knowledge that they emerged. Question 7 finally provides information on Rapid Eye Movement (REM) sleep [17] and can be extended to all variables observed to determine the environmental reasons of sleep disturbances these queries can be self-applied for compounding a sleep log which can be easily applied in a mobile application. Question 7 finally provides information on Rapid Eye Movement (REM) sleep [17] and can be extended to all variables observed to determine the environmental reasons of sleep disturbances.

\subsection{Polysomnography}

Polysomnography (PSG) is the gold standard for a sleep study. PSG (Figure 1) is a history of multiple physiological signals all along with sleep, including electroencephalogram (EEG), electromyogram (EMG), electrooculogram (EOG), photoplethysmogram, and electrocardiogram, the position of the body, abdominal and thorax exertion, implied airflow and various others. EOG, EEG, and EMG signals are analyzed by a specialist to distinguish epochs for thirty-second PSG periods - into one among the sleep or wakefulness stages. PSG is an expensive and cumbersome method not suitable for long-term studies. Characteristic patterns in EEG, EOG and EMG are used to define states and stages of human sleep.

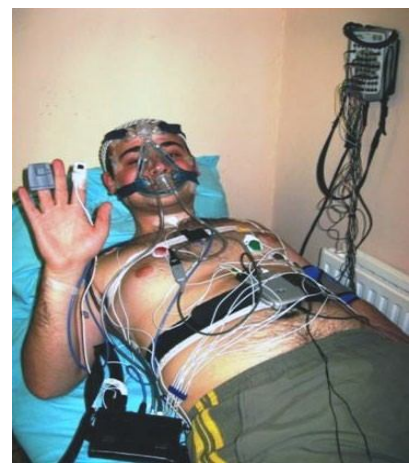

Figure 1: Polysomnography 
Table 1: Sleep stages classification based on EEG, EOG and EMG

\begin{tabular}{|l|l|l|l|}
\hline & Electroencephalogram & Electro-oculogram & Electromyogram \\
\hline Wake (eye open) & Low amplitude, mixed, High frequency & Rapid & High variable \\
\hline Wake (eye closed) & $\begin{array}{l}\text { Low amplitude, alpha (8-13Hz) } \\
\text { dominates over the occipital region }\end{array}$ & $\begin{array}{l}\text { Absent but slow rolling eye } \\
\text { movements }\end{array}$ & Reduced \\
\hline NREM Stage 1 & $\begin{array}{l}\text { Low amplitude, mixed frequency } \\
\text { (alpha absent) }\end{array}$ & Slow rolling eye movements & Reduced \\
\hline NREM Stage 2 & $\begin{array}{l}\text { Low amplitude, K complexes and sleep } \\
\text { spindles }\end{array}$ & Absent & Reduced \\
\hline NREM Stage 3 & $\begin{array}{l}\text { Increased amplitude, Decreased } \\
\text { frequency, 20 to 30\% delta }\end{array}$ & Absent & Reduced \\
\hline NREM Stage 4 & $>50 \%$ dominated by delta EEG activity & Absent & Reduced \\
\hline REM & Low amplitude, mixed frequency & Rapid, conjugate & Absent \\
\hline
\end{tabular}

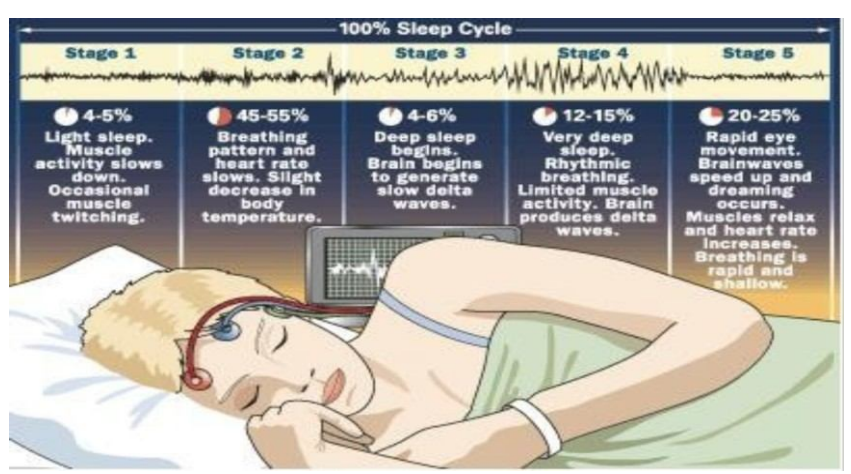

Figure 2: Different sleep stages in a sleep cycle

As shown in Figure 2, a moderately healthy person will undergo up to five whole cycles of night sleep every day. This consists of one cycle of Rapid Eye Movement (REM) stage and four different stages of Non -Rapid Eye Movement (NREM) sleep from NREM1 to NREM4[18]-[20]. The names NREM3 and NREM4 are Deep Sleep, as shown in Figure 3 (a-f). Each NREM sleep period lasts between five andfifteen minutes. NREM1 is the starting of sleep called the transition stage [20]. When a person is at this point, his or her eyes move slowly, the movement of the muscle slows down and he or she can be easily awakened. The eye movement will stop during stage two and the physical consideration such as body temperature and heart rate will be diminished. He or she will be harder to wake up during stage 3 and 4 . Dream sleep is termed as the REM stage, wherein the person sleeps and begins to dream.

The brain and body require a lot of energy at this stage, and it is supplied by high body temperature and heart rate [21]. The utmost familiar assessment for differentiating NREM sleep stages is EEG, whereas the method frequently used to differentiate REM sleep from other stages of sleep is EMG and EOG waveforms. The muscle tone measurement is typically done using the technique of EMG. Table 1 shows the classification of sleep stages of a normal human being using the above measurements. The electrodes transmit electrical signals and cause muscles to contract [22].

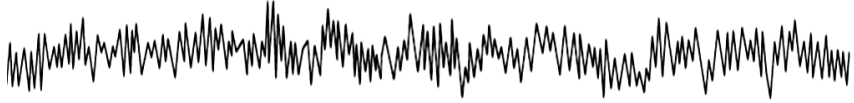

(a) Resting- alpha waves -hypnogogic state

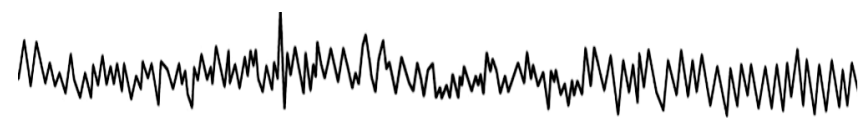

(b) NREM sleep: Stage 1-mix of alpha and theta waves (8-12 cycles/second)

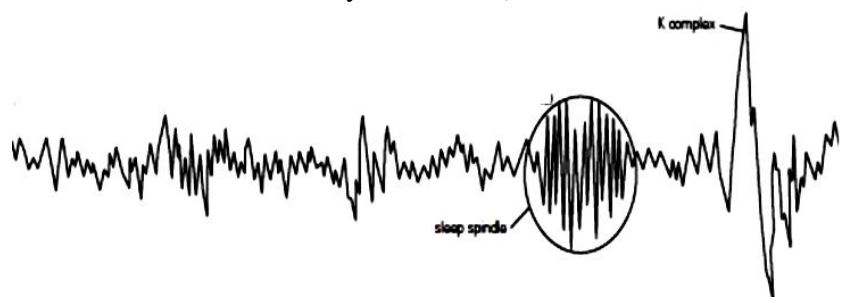

(c) Stage 2-Mostly theta waves, plus occasional sleep spindles and $\mathrm{k}$ complex (3-7 cycles/second)

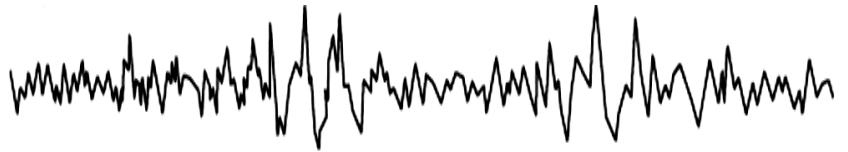

(d) Stage 3- mix of theta waves and delta waves

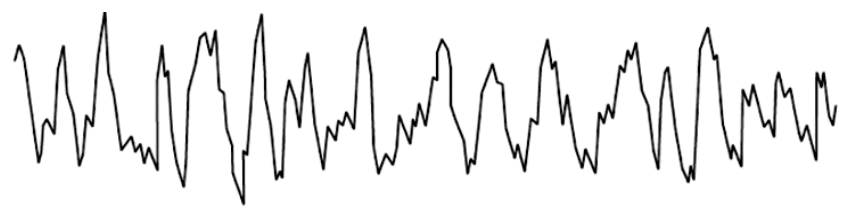

(e) Stage 4- more than $50 \%$ delta waves (1/2- 2 cycles /second)

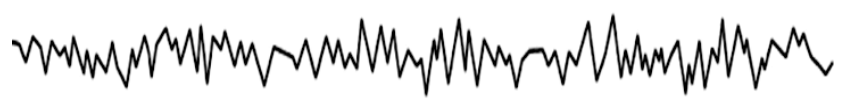

(f) REM Sleep: Irregular fast waves; similar to beta waves

Figure 3: Brain activity at different sleep stages: (a)Resting phase (b) NREM Stage 1 (c) NREM Stage 2 (d) NREM Stage 3 (e) NREM Stage 4 (f) REM Sleep 
An adult sleep for about 8 hours per night, progressing through cycles of approximately 1.5 hours. Sleep gradually progresses from NREM stage 1 to 4 in a period of 45 to 60 minutes after sleep started. After the first slow-wave sleep cycle, NREM stage progression reverses. Deep sleep cycles (NREM4) occur earlier in the night, with REM sleep periods occurring every 90 minutes on average, and the REM interval shortens with age advance. NREM and REM combine with a moderate duration of $90 \mathrm{~min}$ to $110 \mathrm{~min}$ throughout the night. As the sleep period increases, the ratio of each cycle of slow-wave sleep decreases and that of REM increases.

Generally, REM sleep details for 20 to 25 per cent of total sleep, while NREM stages from (1 to 2) account for $50 \%$ to $60 \%$ (moving upwards for the elders), as depicted in Figure 4. Adults sleep a night for a minimum of 1-2 hours of REM, in 4-5 sessions, each improving over time. Speedier onset of REM sleep in an adolescent can indicate pathologies such as circadian rhythm disorders, narcolepsy, endogenous depression, or withdrawal of drugs (especially if less than 30 min). A newborn spends about 50 per cent of the total REM sleep time compared to an adult who spends about 20 per cent of their time in REM sleep.

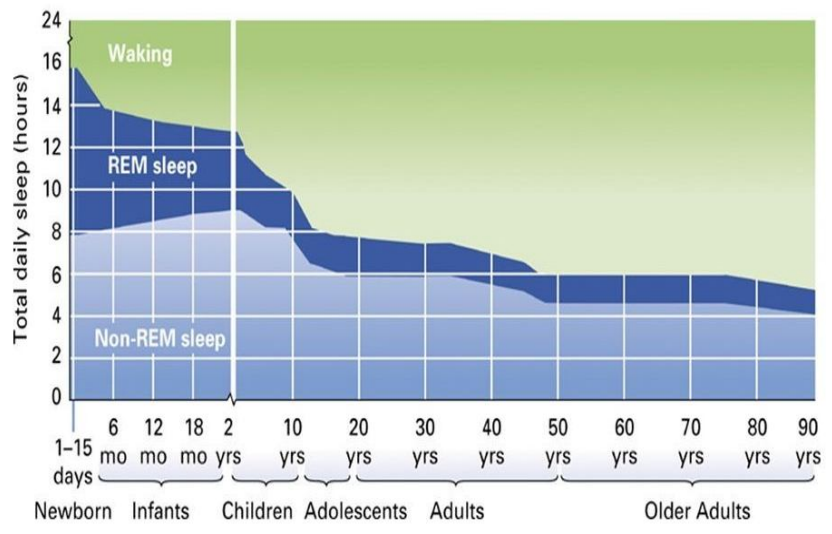

Figure 4: Sleep pattern across the human life span

\section{PROPOSED MODEL}

\subsection{Environmental}

As pointed out by [23], sleep quality was the highest at $32^{\circ} \mathrm{C}$ followed by sleep quality at $28^{\circ} \mathrm{C}$, while the quality of sleep was the worst at values $36^{\circ} \mathrm{C}$ and $38^{\circ} \mathrm{C}$. The notable repercussions of elevated temperatures on sleep quality were primarily expressed in shallow sleep and length of sleep. The effect of temperature is considerable on the stillness of sleep, trouble in falling asleep, the fulfillment of sleep and adequacy of sleep. The side effects on temperature on those four points were important. Higher temperatures led to a reduction in the temperature of the body and a rise in moderate values of respiratory rate and heart rate. Wakefulness thus increases, and SWS (slow-wave sleep) declined. The other parameter that can influence heat transfer and consequently the quality of sleep is the humidity. As pointed out by [24] a variety of theories were suggested to clarify the regulation of the sleep structure. The most accepted hypothesis is the circadian homeostatic interaction model. It recommends that humid heat can influence sleep over the homeostatic pathway, probably interfere with adenosine accumulation in the basal forebrain and thus affect the sleep transition point of the non-rapid eye movement (NREM). Also well-known is the link between severe moisture and respiratory illness that has detrimental effects on sleep. Sleep is disrupted by humidity [24] at a high ambient temperature due to the unfavorable effect on evaporative heat loss. Research with head cooling and air current found that manipulations to conductive heat transfer and/or reverse convective would aid in the control of sleep with down-regulated evaporation.

\subsection{Luminosity and Motion}

It is clear how the circadian cycle is affected by the artificial lighting. This happens since intense artificial light quench melatonin, the "sleep hormone," the nocturnal secretion [25]. In addition, humans in the segment of short-wavelength of the light spectrum demonstrate the strongest reaction of melatonin restraint, otherwise termed as the blue lights. The blue monochromatic light [26] has been found to be more competent than long-wavelength light to enhance focus and disrupt circadian rhythms. Therefore, with respect to white and blue luminous intensity, the light measured in the room presents the evidence of sleep latency disorders. Another significant factor to be considered is the motion to determine how calm the rest was. By recording sleep movement information,it can be compared with various other information, such as temperature and humidity, noise levels, and a basic sleep anamnesis to further analyze the causes of self-perception of sleep, partial arousals and microawakenings.

\subsection{Proposed Prototype}

This paper presents a non-invasive sleep-environment monitoring system to aid diagnose factors which may lead to poor sleep, in order to evade the high costs and to conduct an assessment in loco. The proposed microcontroller-based system uses a sensor array to accomplish data acquisition of variables that could potentially affect sleep quality, such as temperature, humidity, luminosity, and motion. In addition to a basic sleep log, this will provide doctors and technical staff more accurate information, reduce costs, aid with the screening process and help enhance the health of people suffering from sleep disorders. The proposed device is built to provide robustness, usability and scalability for a fully integrated sleep assessment system which depends on microcontrollers, array sensors and a single-board computer to improve the fiscal viability of a broad application.

Using the Arduino Uno board, light-dependent resistor (LDR)/ photo-resistor, DHT11 as an ambient sensor, vibration sensor for body condition and the monitoring system has been created, as shown in the block diagram (Figure 5). Arduino IDE is programmed with sensor 
algorithms to empower those sensors and allow them to verify the value captured from the ambience of the room and the body condition. On the Serial Monitor, the obtained value of light intensity, temperature, ambient humidity, body temperature and user activity will be shown. The DHT11 sensor is a fusion of a thermistor and a capacitive humidity sensor for reading the analog value of surrounding

Figure 5: Block diagram of the proposed prototype

temperature as well as humidity. The humidity sensor reports nocturnal sweat. LDR which acts as a light sensor is used to calculate the amount of light in the surrounding area. A vibration sensor is used to detect if the person is moving or

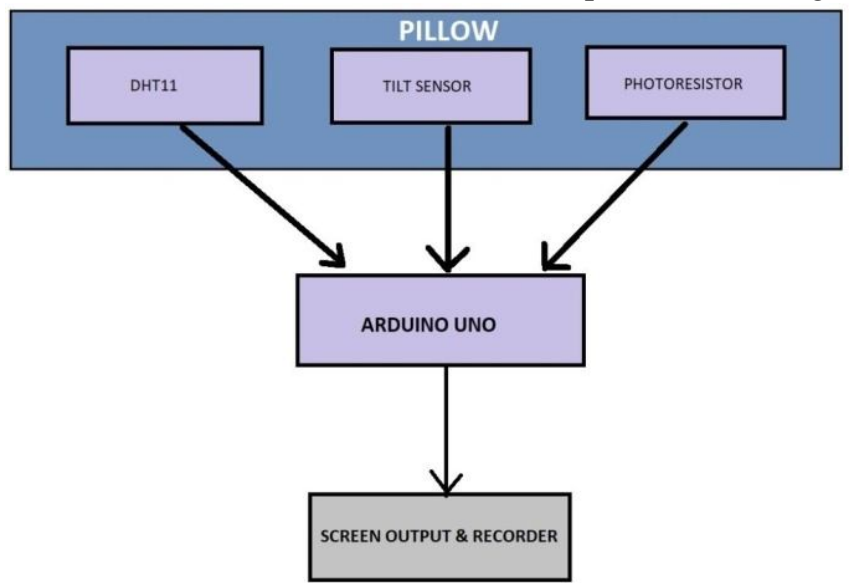

making side turns (from right to left or vice versa) while sleeping.

\section{EXPERIMENTAL RESULTS AND DISCUSSION}

The experimental setup shown in Figure 6 measures light intensity, ambient temperature and room humidity. The list of components used in the experimental setup is tabulated in Table 2. Intensity of light are measured using the LDR sensor. For each of five sets of conditions, ten readings were taken which are dim, dark, very dark, light and very bright conditions. The value of light intensity is found with a range between 0 and 1023, depending on the digital value. In condition 1, the light intensity value is recorded between the ranges from 1 to 9 referring to very dark surroundings such as throughout the night, and the light is switched off inside the room. For condition 2, the value is between 10-20 ranges, showing dark surroundings like early morning and turning off the lights. The frequency of light varies between 21 and 45 for condition 3, which applies to dark conditions such as in the morning or late in the evening. First, condition 4 reported the value of light intensity between the 70 to 487 ranges pointing at the house in the afternoon towards the bright surrounding. Finally, condition 5 reports the light intensity between the 501 to 1021 ranges suggesting very bright surroundings like outside the house in the afternoon.

Room humidity readings are assessed using DHT11 sensor. Consideration is given to 10 readings which are dry, medium or moist. Based on the data considered, the dry state humidity level varies from 1 to 20 per cent RH suggesting a dry environment during the sunny day, such as afternoon and evening. The calculated reading is between 21 and 60 per cent $\mathrm{RH}$ for temperate weather. The reading shows mild humidity in many local environments, for example during exercise. Humidity levels range from 61 to 85 per cent RH which is related to the humid state when it has been raining for quite a long time and right after the rain when the temperature islow.

The experiment is performed in five distinct conditions, which are cold, very cold, very hot, hot and mild. The reading is registered between 18 and 22 degrees Celsius in very cold environments such as indoors with an air conditioner or during heavy midnight rains. Cold temperatures have a temperature range between $23^{\circ}$ and $27^{\circ}$ centigrade. The reading is collected during early mornings or immediately after a rain for the cold weather. The normal state has a temperature range from $29^{\circ}$ to $33^{\circ}$ centigrade. Temperature varies between $37^{\circ}$ and $40^{\circ}$ Celsius for very hot weather. The reading can be taken during the afternoon or evening exterior to the house. To measure the body temperature with high accuracy, temperature sensor can be used but a stable reading takes about 35 seconds. Experiments are performed with various ambient conditions, and the performance is compared.

Table 2: Hardware Components

\begin{tabular}{|c|}
\hline Component Name \\
\hline Arduino Uno \\
\hline DHT11(temperature and humidity sensor) \\
\hline Tilt sensor(vibration sensor) \\
\hline Photoresistor (lighting sensor) \\
\hline Breadboard \\
\hline Jumper wires \\
\hline Resistors (10k $\Omega$ and $1 \mathrm{M} \Omega$ ) \\
\hline
\end{tabular}

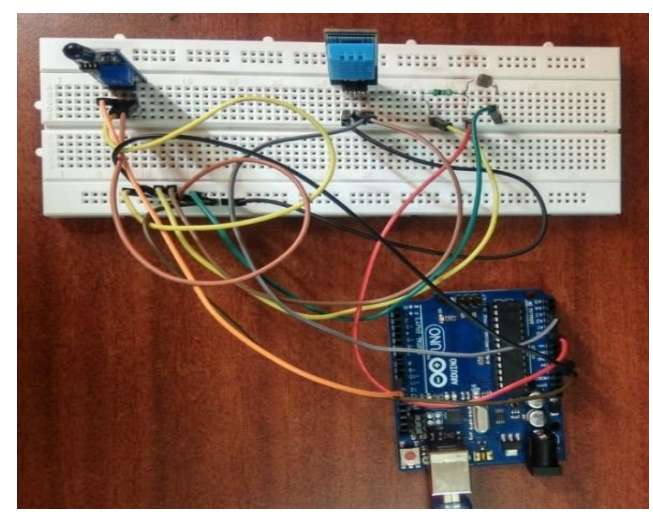

(a) 


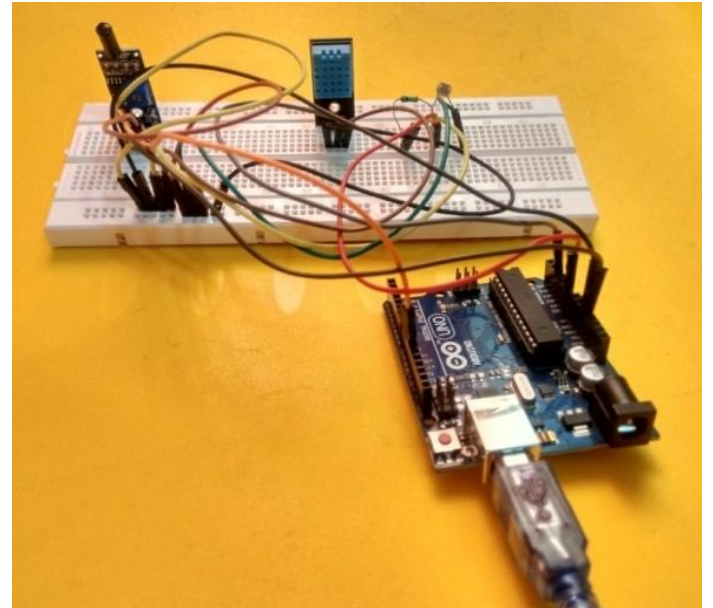

(b)

Figure 6: Experimental setup: (a) Top view (b) Lateral view

The patient's motion during sleep is indicated by a transition from M1 to M0 or vice versa. It is detected using the vibration sensor whenever the person moves and displayed as M0 on the serial monitor. The data of different sleep records under different ambient conditions is presented in Figure 7 and Figure 8. A daily report with sample data is presented in Table 3.

COM4 (Arduino/Genuino Uno)

\section{M1}

Luninosity: 26 , Current humidity $=50.008$ Temperature $=26.00 \mathrm{C}$ Iuninosity: 12 , Current humidity $=58,005$ tenperature $=27.00 \mathrm{C}$ Luninosity: 20 , Currest humidity $=58.004$ Tezperature $=27,00 \mathrm{C}$ Iuminosity: 15 , Current hunidity $=57.004$ Tesperature $=27.00 \mathrm{C}$ Iuminosity: 17 , Current humidity $=57.004$ Tenperature $=27.00 \mathrm{C}$ No

M!

Luminosity: 10 , Current humidity $=56,004$ tenperature $=27,00 \mathrm{C}$ Luninosity: 9, Curzent hunidity $=62.005$ Tenperature $=27.00 \mathrm{C}$ Iuminosity: 11 , Current hunidity $=58.004$ Temperature $=27.00 \mathrm{C}$ Iuninosity: 12 , Current humidity $=57.004$ Temperature $=27.00 \mathrm{C}$ Luminosity: 12 , Current humidity $=57,008$ tenperature $=27.00 \mathrm{C}$

(a)

\section{CoM4 (Arduino/Genuino Uno)}

$\mathrm{M} 1$

Luminosity: 22 , Current humidity $=89.004$ Tenperature $=25.00 \mathrm{C}$ Luninosity: 10 , Current humidity $=89.004$ Tenperature $=25.00 \mathrm{C}$ Luninosity: 7, Current humidity $=89.004$ Temperature $=25.00 \mathrm{C}$ Laninosity: 4, Current humidity $=89.004$ Temperature $=25.00 \mathrm{C}$ $\mathrm{No}$

K1

$\mathrm{x} 0$

M1

Luminosity: 7, Current humidity $=89.004$ Temperature $=25.00 \mathrm{C}$ Luninosity: 49 , Current humidity $=89.006$ tenperature $=25.00 \mathrm{C}$ Luminosity: 6, Curreat humidity $=89.004$ Temperature $=25,00 \mathrm{C}$

(b)

Figure 7: (a) Values of parameters recorded in Serial Monitor when luminosity is high (b) Values of parameters recorded in Serial Monitor when humidity is high

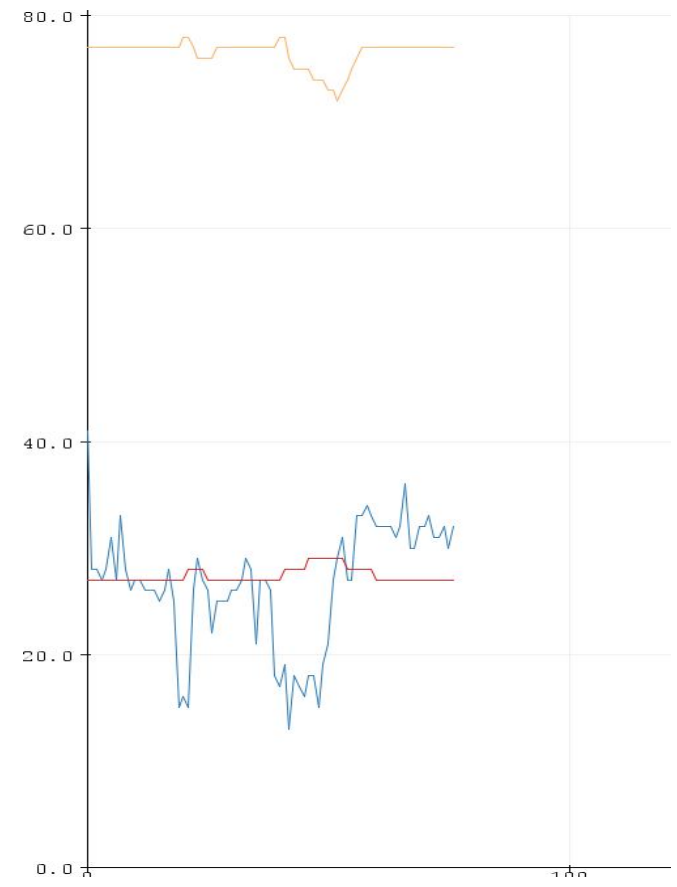

(a)

COM4 (Arduino/Genuino Uno)

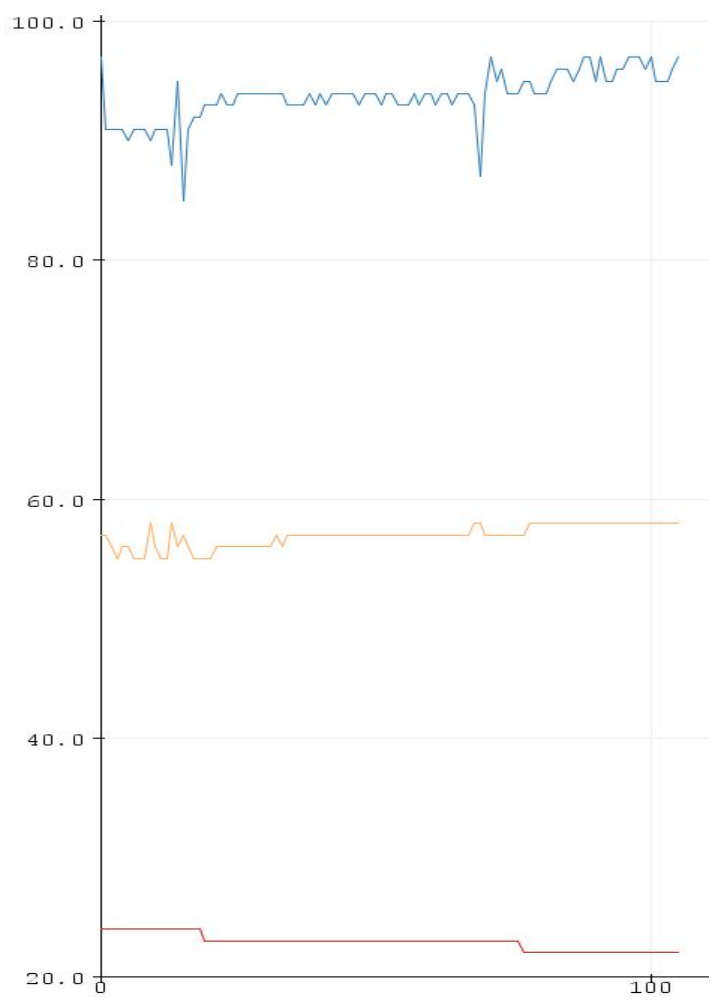

(b)

Figure 8: (a) Values of humidity, luminosity and temperature (from top to bottom) recorded for a small sleep duration on a rainy day with lights off (b) Values of luminosity, humidity and temperature (from top to bottom) recorded in Serial Plotter for a small sleep duration on a normal day with lights on. 
Table 3: Daily report with sample data

\begin{tabular}{|l|}
\hline \multicolumn{1}{|c|}{ Item Value } \\
\hline Bedtime ------------ - 00:08 \\
\hline Wake up time---------- 07:08 \\
\hline Sleep time -------------7 h \\
\hline Body Temperature ----------36.5/36.8 ${ }^{\circ} \mathrm{C}$ \\
\hline Sweat ------------------94\% \\
\hline Turns ------------------37 \\
\hline
\end{tabular}

\section{CONCLUSION}

A portable sleep monitoring system is developed for the ambience and body condition. Using the functionality test, the sleep patterns at various different ambient conditions are recorded. The paper introduces a smart temperature sensor-based pillow and a humidity sensor that forms the core element of the sleep monitoring system. Precisely, a report is provided on a daily basis by analyzing pillow time-series data, that faithfully emulates a user's sleep status like a camera, but provides additional details such as sweat and body temperature. In the serial plotter, summary on a daily basis is presented visually to the user. From the weekly or monthly sleep data, the user is able to track the day-to-day dynamic sleep status and appropriate action can be taken specifically to concentrate on the quality of his / her sleep or seeking a doctor's advice. The statistical data can be collected from all users, and their average sleep rates can be diagnosed. This will conclusively help the patient to improve their safety and quality of their sleep. Body temperature and sweat calculation are only the health sensing device and the system can be improved by incorporating other clinical measures such as blood pressure and heart rate into the pillow.

\section{REFERENCES}

1. Harvey, A.G., Stinson, K., Whitaker, K.L., Moskovitz, D. and Virk, H., 2008. The subjective meaning of sleep quality: a comparison of individuals with and without insomnia, Sleep, Vol. 31, no. 3, pp. 383-393, March 2008.

2. Suzuki T., Ouchi K., Kameyama K. and Takahashi M. (2009). Development of a sleep monitoring system with wearable vital sensor for home use. In Proceedings of the International Conference on Biomedical Electronics and Devices - Volume 1: BIODEVICES, Portugal, 2009, pp. 326-331.

3. Buxton, Orfeu M, and Enrico Marcelli. Short and long sleep are positively associated with obesity, diabetes, hypertension, and cardiovascular disease among adults in the United States. Social science \& medicine (1982) vol. 71, no. 5, pp. 1027-1036, Sept.2010.

4. J. M. Mullington, M. Haack, M. Toth, J. M. Serrador, and Meier Ewert.Cardiovascular, inflammatory, and metabolic consequences of sleep deprivation.Progress in Cardiovascular Diseases, Vol. 51, no. 4, pp. 294-302, Jan-Feb 2009.

5. K. Koskenvuo, C. Hublin, M. Partinen, T. Paunio, and M. Koskenvuo. Childhood adversities and quality of sleep in adulthood: A population-based study of 26,000 Finns.Sleep Medicine, Vol. 11, no. 1, pp. 17-22, Jan. 2010.

6. Karlson C. W., Gallagher M. W., Olson C. A., and N. A. Hamilton. Insomnia symptoms and well-being: Longitudinal follow-up.Health Psychology, Vol. 32, no. 3, pp. 311-319, March 2013.

7. Roth and Thomas. Insomnia: definition, prevalence, etiology, and consequences. Journal of clinical sleep medicine: JCSM: official publication of the American Academy of Sleep Medicine, Vol. 3,5 Suppl (2007): S7-10, August 2015.

8. Korpinen, Leena, Pääkkönen and Rauno.Self-reported sleep disorders/disturbances associated with physical symptoms and usage of computers. International Journal of Industrial Ergonomics, Vol. 43, no. 4, pp. 257-263, July 2013.

9. F. P. Cappuccio, Taggart F. M., N.B. Kandala, A. Currie, E. Peile, S. Stranges, and M. A. Miller. A meta-analysis of Short Sleep Duration and Obesity in Children and Adults. Sleep, Vol. 31, no. 5, pp-619-626, May 2008.

10. Pagel J. F. and C.F.Kwiatkowski. Sleep Complaints Affecting School Performance at Different Educational Levels.Frontiers in Neurology, Vol. 1, Nov. 2010.

11. E. M. O'Brien and J. A. Mindell.Sleep and risk-taking behavior in adolescents. Behavioral Sleep Medicine, Vol. 3, no.3, pp. 113- 133, June 2010.

12. Carney C. E.,J.D.Edinger,B.Meyer, L.Lindman and TIstre.Daily activities and sleep quality in college students. Chronobiology International, Vol. 23, no. 3, pp. 623-637, Jan. 2006. https://doi.org/10.1080/07420520600650695

13. Sleep Disorders 2016http://www.sleepfoundation.ord/

14. M. S. Aldrich.Abnormal sleep: impact, presentation, and diagnosis, inPrinciples and Practice of Sleep Medicine, 4th ed., Kryger MH, Roth T, Dement WC, Ed. Philadelphia: Elsevier/Saunders,2000, pp.521-525.

15. Sadeh A. and Acebo C.The role of actigraphy in sleep medicine.Sleep Medicine Reviews, Vol. 6, no. 2, pp. 113-124, April 2002.

16. K. Yoshimura, Y. Oka, T. Kamoto, K. Yoshimura, and O. Ogawa. Differences and associations between nocturnal voiding/nocturia and sleep disorders. $B J U$ International, Vol. 106, no.2, pp. 232 - 237, June 2010.

17. S.KawanoandK.Ogawa.Relationshipbetweenthedrea 
mpropertyscaleandphysiologicalactivitiesduringRE

Msleep.International Journal of Psychophysiology, Vol. 94, no. 2, Nov.2014.

18. Casey S.J.,Solomons L.C.,J.Steier, N.Kabra,A.Bumside, M.F.Pengo,Moxham J.,L.H. Goldstein and M.D.Kopelman.Slow wave and REM sleep deprivation effects on explicit and implicit memory during sleep.Neuropsychology, Vol. 30, no. 8,pp. 931-945, Nov. 2016.

19. Carskadon, M.A. and Dement. Monitoring and staging human sleep in Principles and practice of sleep medicine, 5th edition, M.H. Kryger, T. Roth, \& W.C. Dement, Ed. St. Louis: Elsevier Saunders, 2005, pp. 13-23.

20. Şen B., Peker M., Çavuşoğlu A. and Çelebi F.V.A comparative study of sleep stage based on EEG signals using feature selection and classification algorithms.Journal of medical systems, Vol.38, no. 18, March 2014.

21. Jhaveri K. A., Trammell R. A., and Toth L. A. Effect of environmental temperature on sleep, locomotor activity, core body temperature and immune responses of $\mathbf{C 5 7 B L / 6 J}$ mice.Brain, behaviour, and immunity, Vol. 21, no. 7, pp. 975-987, April 2007.

22. W.-C. Liao, L. Wang, C.-P. Kuo, C. Lo, M.-J. Chiu and $\mathrm{H}$ Ting. Effect of a warm footbath before bedtime on body temperature and sleep in older adults with good and poor sleep: An experimental crossover trial.International Journalof Nursing Studies, Vol. 50, no. 12, pp. 1607-1616, Dec.2013.

23. Guozhong Zheng, Ke Li and Yajing Wang. The Effects of High-Temperature Weather on Human Sleep Quality and Appetite. International Journal of Environmental Research and PublicHealth, Vol.16 no.2, Jan. 2019.

24. M. D. Manzar, M. Sethi, and M. E. Hussain.Humidity and sleep: a review on the thermal aspect.Biological Rhythm Research, Vol. 43, no. 4, pp. 439-457,Sept. 2011.

25. A. J. Lewy, T. A. Wehr, F. K. Goodwin, D. A. Newsome, and S. P. Markey. Light suppresses melatonin secretion in humans.Science, Vol. 210, no. 4475, pp. 1267-1269, Dec. 1980.

26. West K. E., Jablonski M. R., Warfield B., K. S. Cecil, M. James, M. A. Ayers, J. Maida, Bowen C., D. H. Sliney, M. D. Rollag, Hanifin J. P., and G. C. Brainard. Blue light from light-emitting diodes elicits a dose-dependent suppression of melatonin in humans.Journal of Applied Physiology, Vol. 110, no. 3, pp. 619-626, March 2011.

https://doi.org/10.1152/japplphysiol.01413.2009 